\title{
Flexible Manufacturing Systems Performance Analysis and Improvement
}

\author{
Habtamu Tesfaye ${ }^{1}$, Getu Girma ${ }^{2}$ \\ ${ }^{1-2}$ School of Mechanical \& Industrial Engineering, Dire Dawa Institute of Technology
}

Dire Dawa University, Dire Dawa

Ethiopia

\begin{abstract}
Due to the intense market competition, managements of manufacturing industries are striving to optimize their manufacturing lead times, enhance quality of products, increase part variety, and reduce production cost. Thus, the trend towards market globalization requires these manufacturing environments to be designed, analyzed for its performance and improved in such way that it can cater the market place challenges to survive and grow in the sector. In this paper a case study of Hibret Manufacturing \& Machine Building Industry (HMMBBI) in flexible manufacturing system (FMS) shop is presented. The goal of the study is to analyze the performance of FMS and propose a performance improvement method. Analytical methods of performance analysis-bottleneck model and its extension called 'extended bottleneck model' are applied to determine the current production rate and the percentage workstations utilization of the existing FMS shop. The proposed FMS with balanced workloads between work stations has shown a significant improvement in percentage utilization of workstations, production lead time and as well as production throughput.
\end{abstract}

Keywords: Flexible Manufacturing System, Bottleneck, Extended Bottleneck, workstations utilization, Performance analysis

\section{INTRODUCTION}

In today's competitive, dynamic, and unpredictable business environments, it is necessary to measure and improve manufacturing performance to be able to compete in the market. The need for meeting dynamic customers' demands for a variety of products, fast and reliable delivery initiated the implementations of the concept of flexibility in manufacturing industries and thus, the flexible manufacturing systems (FMS). FMS is a computer-controlled production system, that integrate different standalone machines and control equipment's capable of processing a variety of part types (El-Tamimi et al., 2012; Yadav \& Jayswal, 2018). According to Groover (2015) has defined FMS as an integrated system composed of automated workstations such as computer numerically controlled machines with the tool changing capability, material handling and storage system and a computer control system which controls the operations of the whole system. The types, major components and level of flexibility are clearly described by Groover (2015), Jovanovi (2015), De Toni \& Tonchia(1998) and Maccarthy \& Liu (1993). It is clear that FMS has a great impact on the success of manufacturing industries if implemented properly and managed well. Therefore, the analysis of FMS performance is very critical to improve and sustain the proper functioning of the system and aid managements in the process decision making process.

This paper was attempting to evaluate the performance of an existing flexible manufacturing system and proposed modified FMS. The remaining part paper is organized in the following manner; section 2 is the related literature review; section 3 is a methodology and materials; section 4 is result and discussion; section 5 presents proposed system followed by conclusion in section 6 and final section provides the list of references which have been cited accordingly. 


\section{LITERATURE REVIEW}

Recently, researchers are attracted in the area FMS such as scheduling and machine loading, cell formation, performance analysis to get the optimal value of throughput time and equipment utilization (Mahmood et al., 2017). Flexibility is an attribute that allows a mixed model manufacturing system to cope up with a certain variations in part or product style, without having any interruption in production due to changeovers between models (Pandey R. et al, 1984). Manufacturing companies look for ways to compete and become order-winners especially where the current market faces rapid changes of the customer requirement and product specification. To deal with these changes, it is necessary for a manufacturing system to conform to these changes as quickly as possible in order to remain competitor in the market. This development leads to a conflict for a manufacturing system due to the decrease in productivity while variety increases. So, the flexible manufacturing system is a good method that can combine between variety and productivity(El-Tamimi et al., 2012).

The framework of flexible manufacturing systems (FMSs) combines high productivity, quality and flexibility needed for the fast response to changing market demands. FMS is actually an automated set of numerically controlled machine tools and material handling systems, capable of performing a wide range manufacturing operation with quick tooling and instruction changeovers. The term flexible manufacturing system (FMS) is generally used to represent a wide variety of automated manufacturing systems. Flexible Manufacturing System (FMS) can be defined as an integrated system composed of automated workstations such as computer numerically controlled (CNC) machines with tool changing capability, a hardware handling and storage system and a computer control system which controls the operations of the whole system (Singholi et al., 2010).

The important factors in the design of FMS are having high investment and decisions made in planning for the system must ensure compatibility between the automated manufacturing system and the demands of the market that can be changed at any time. Flexible manufacturing system is recognized to have ten types(Taha, 2015); machine flexibility, material handling flexibility, operation flexibility, process flexibility, product flexibility, routing flexibility, volume, flexibility, expansion flexibility, control flexibility, and production flexibility. Flexible manufacturing systems have constituted an active area of interest in operations research, and many of the important contributions. The performance of the FMS and operating problems can be analyzed under four different approaches(Groover, 2015; Jovanovi, 2015); deterministic model, queuing model, discrete event simulation, and other approaches, including heuristics.

The number of finished parts was considered as the system performance measure. In recent studies pertaining to the FMS, researchers have been very keen to improve the performance of flexible manufacturing system. Some researchers have used deterministic models to estimate the FMS performance; these models are very useful for estimating system parameters such as production rate and resource utilization at a beginning stage of design. Solberg and Mejabi presented a universally accepted mathematical model (deterministic in nature) to evaluate various performance measures of an FMS (Ebrahimi, 2015) Among these quantitative flexible manufacturing system analysis techniques, the deterministic model is adopted to evaluate the performance an existing FMS understudy. Deterministic models are useful in obtaining starting estimates of the system performance parameters such as production rate, capacity, and utilization. They do not permit evaluation of operating characteristics such as the build-up of queues and other dynamics that can impair performance of the production system.

FMS is useful to implement in the area of both flow and job shop industries, despite the complexity that may exist when it is applied in the production due to level of flexibility than can be accepted. Some of gained benefits from an FMS are: increase in the use of machine, fewer machines to be utilized in process, less space needed in the factory, fit any change, decline in inventory demands, less manufacturing lead time, improved productivity and great chance to have automated production (Abazari et al., 2012).

One of the major issues that may happen in manufacturing system is bottleneck. A bottleneck is defined as the failure of machine to work well which affects the performance of the manufacturing system. It can be also described as the one that is the most sensitive in the production line. It causes the process to be slow, reduce the productivity and delay in project; hence it will make loss to the company(Small, 2015; Taha, 2015). 


\section{METHODS AND MATERIALS}

\subsection{Methods}

Important aspects of FMS performance can be mathematically described by a deterministic model called the bottleneck model, developed by Solberg (El-Tamimi et al., 2012; Jovanovi, 2015; Sharma, 2013). The bottleneck model is simple and intuitive used to provide starting estimates of FMS performance parameters such as production rate, number of workstations, etc. The term bottleneck refers to the fact that an output of the production system has an upper limit, given that the product mix flowing through the system is fixed. The basic parameters, and symbols used for mathematically modeling FMS as bottleneck model are adopted from Groover (2015) and defined as follows:

i. $\quad$ Part mix: The mix of the various parts or product styles produced by the system is defined by $\mathrm{P}_{\mathrm{j}}$, where $\mathbf{P}_{\mathbf{j}}$ the fraction of the total system output that is of style $\mathbf{j}$ (El-Tamimi et al., 2012; Sharma, 2013). The subscript $\mathrm{j}=1,2, \ldots, \mathrm{p}$, where the total number of different part styles made in the FMS during the time period of interest and the value of $P_{j}$ must sum to unity.

$$
\sum_{j=1}^{n} P j=1.0
$$

ii. Workstation and number of servers: The FMS has a number of distinctly different workstations $\boldsymbol{n}$ and $\mathbf{s}_{i}$ is the number of servers at the $\mathbf{i}^{\text {th }}$ workstation, where $i=1,2, \ldots, \mathrm{n}$. In the terminology of the bottleneck model, each workstation may have more than one server, which means that it is possible to have two or more machines capable of performing the same operations.

iii. Operation frequency $\left(\mathbf{f}_{\mathrm{ijk}}\right)$ : The operation frequency is defined as the expected number of times a given operation in the process routing is performed for each work unit. Where the designations subscript $\mathrm{i}, \mathrm{j}, \& \mathrm{k}$ refers to the station, process plan, and the operations frequency respectively.

iv. Process routing: For each part or product, the process routing defines the sequence of operations, the workstations where operations are performed, and the associated processing time. The sequence includes the loading operation at the beginning of processing on the FMS and unloading operation at the end of processing. Let be $t_{\mathrm{ijk}}$ is the processing time, which is the total time that a production unit occupies a given workstation server, not counting any waiting time at the station. Processing time is designated by $\left(\mathbf{t}_{\mathbf{i j k}}\right)$.

Where:

$i$ - Refers to the station,

$j$ - Refers to the part or product

$k$ - Refers to the sequence of operations in the process routing

v. Work handling system: The material handling system used to transport parts or products within the FMS can be considered to be a special case of a workstation. The material handling station is designated $n+1$, and the number of carriers in the system (e.g. conveyor carts, AGVs, etc.) is analogous to the number of servers in a regular workstation represented by $\mathbf{s}_{\mathbf{n}+\mathbf{1}}$.

vi. Transport time: Is the mean time required to move a part between stations in the process routing designated by $t_{n+1}$. It is computed for individual transport based transport velocity and distances between stations in the FMS, but it is more convenient to simply use an average transport time for all moves in the FMS (El-Tamimi et al., 2012; Groover, 2015; Sharma, 2013). 
International Journal of Advances in Scientific Research and Engineering (ijasre), Vol 6 (10), October -2020

\subsection{Operational parameters for FMS}

Using the above terms, the certain average operational parameters of the production system such as average workloads of stations can be defined. The average workload for a given station is defined as the mean total time spent at station per part. It is calculated as:

$$
W L_{i}=\sum_{j} \sum_{k} \boldsymbol{t}_{i j k} \boldsymbol{f}_{i j k} \boldsymbol{P}
$$

Where:

- $\mathrm{WL}_{\mathrm{i}}-$ Average workload for station $i$,

- $\mathrm{t}_{\mathrm{ijk}}-$ Processing time for operation $k$ in part $j$ at station $i$,

- $\mathrm{P}_{\mathrm{j}}-$ Part mix fraction for part $j$

The workload of the handling system is the mean transport time multiplied by the average number of transports required to complete the processing of work part. The average of transport required completing the processing of a work part, $\mathrm{n}_{\mathrm{t}}$ is computed using;

$$
\boldsymbol{n}_{t}=\sum_{i} \sum_{j} \sum_{k} \boldsymbol{f}_{i j k} \boldsymbol{P}_{j}-\boldsymbol{I}
$$

\subsection{FMS Performance Measures}

Basic FMS performance measures such as production rate of all parts, production rate of each part style, utilization of the different workstations, and number of busy servers at each workstation are analytically computed using Eq. (4) to (9).

i. Maximum production rate: the maximum production rate determined by the capacity of the bottleneck station is computed as;

$$
R_{p}^{*}=S^{*} / W L^{*}
$$

Where:

$R_{\mathrm{p}}{ }^{*}$ - maximum production rate of all part styles produced by the system,

$S^{*}$ - number of servers at the bottleneck station,

$W L^{*}$ - workload at the bottleneck station.

The value of $R^{*}$ includes parts of all styles produced in the system. Individual part production rates can be obtained by multiplying $R^{*}$ by the respective part mix ratios. That is,

$$
\operatorname{Rpj}=\operatorname{Pj}\left(R_{p} *\right)
$$

ii. Utilization of individual workstations: The mean utilization of each workstation is the proportion of time that the servers at the station are working and not idle computed using the formula (Jovanovi, 2015):

$$
\boldsymbol{U}_{i}=\frac{W L i}{S i}\left(R_{p}{ }^{*}\right)
$$

Where:- $\mathrm{U}_{\mathrm{i}}$ - utilization at station $i$,

$\mathrm{WL}_{\mathrm{i}}$ - workload of station $i$,

$\mathrm{S}_{\mathrm{i}}$ - number of servers at $i$,

$\mathrm{R}_{\mathrm{p}}{ }^{*}$ - overall production rate

iii. Average utilization of FMS: The utilization of the bottleneck station is $100 \%$ at the maximum production rate. To obtain the average station utilization, one simply can compute the average values for all stations, including the transport system as; 
International Journal of Advances in Scientific Research and Engineering (ijasre), Vol 6 (10), October -2020

$$
\bar{U}=\frac{\sum_{i=1}^{n+1} U i}{n+1}
$$

iv. Overall Utilization of the System: The overall system utilization is determined as weighted average, were the transport system is omitted from the average. Groover (Groover, 2015) defines the overall utilization mathematically as:

$$
\bar{U}_{\text {system }}=\frac{\sum_{i=1}^{n+1} S i * U i}{\sum_{i=1}^{n} S i}
$$

v. Identification of bottleneck station: Bottleneck station is the busiest station running at its maximum production rate. According to Groover (Groover, 2015), the number of busy stations is estimated by:

$$
B S_{i}=W L_{i} * R_{p}^{*}
$$

Where: - $\mathrm{BS}_{\mathrm{i}}$ - Number of busy servers on average at station $i$ and $\mathrm{WL}_{i}-$ Workload at station $i$.

\subsection{Extended Bottleneck Model}

According to Solberg (1981), the assumption of $100 \%$ stations utilization makes the bottleneck model overly optimistic and results in longer lead time. Therefore, the extension of bottleneck is proposed to overcome the limitations of simple bottleneck model (Jovanovi, 2015). The extended bottleneck model correlates the work-inprocess (WIP) and manufacturing lead time on the basis of the following assumptions to:

i. Closed queue network in which there are $\mathrm{N}$ number of parts in the system.

ii. The product mix flowing through the system is fixed.

iii. Parts visit the stations only once.

iv. System has in-built bottleneck.

The relationship between the work-in-process and manufacturing lead time is then mathematically expressed as in Eq.(11) (for detail a reader can see (Groover, 2015; Jovanovi, 2015))

$$
M L T=\sum_{i=1}^{n} \boldsymbol{W L} i+W L_{n+l}+T_{w}
$$

Where;

$\sum_{i=1}^{n} \boldsymbol{W} \boldsymbol{L} i$ - Summation of average workloads over all stations in the FMS

$\mathrm{WL}_{\mathrm{n}+1}$ - Workload of the part handling system

$\mathrm{T}_{\mathrm{w}}$ - Mean waiting experience by a part due to queues at the station

Then the WIP or $\mathrm{N}$ is defined by the relation:

$$
N=R_{p}^{*}(M L T)
$$

Where; $\mathrm{N}$ - Expected parts waiting for processing (WIP)

$$
\mathrm{R}_{\mathrm{p}} \text { - Production rate }\left(\mathrm{R}_{\mathrm{p}}{ }^{*}\right)
$$

MLT - Manufacturing lead time

\subsection{Materials}

All the data and materials of the study are gathered through direct observation and review of production backlogs. The studied shop consists of two heavy duty lines composed of NC-machineries such as CNC lathes, CNC millings, radial drill, horizontal boring (slotting), and grinding intended on producing a wide variety of machine parts. Variety of parts mixes are produced in this shop, but this study considers only nine-part families those which are frequently ordered 
and produced in the shop. The lists of these products with their processing routes, processing time, frequency they visit each station, and part mix ratio obtained from the company's route sheet backlog is given in the table 1.

Table 1: Product mix and processing time

\begin{tabular}{|c|c|c|c|c|c|c|}
\hline Part (j) & $\begin{array}{c}\text { Part mix } \\
\quad\left(\mathbf{P}_{\mathbf{j}}\right)\end{array}$ & $\begin{array}{l}\text { Operation } \\
(\mathbf{k})\end{array}$ & Description & $\begin{array}{l}\text { Station } \\
\text { (i) }\end{array}$ & $\begin{array}{c}\text { Process } \\
\text { time } \mathbf{t}_{\mathbf{i j k}} \\
(\mathrm{hr} .)\end{array}$ & $\begin{array}{l}\text { Frequency } \\
\quad\left(\mathbf{f}_{\mathbf{i j k}}\right)\end{array}$ \\
\hline \multirow{4}{*}{$\begin{array}{c}\text { Roller } \\
\text { scraper shaft }\end{array}$} & \multirow{4}{*}{0.01235} & 1 & Load/unload & 1 & 0.5 & 1 \\
\hline & & 2 & Mill & 3 & 4 & 1 \\
\hline & & 3 & Turning center & 2 & 6.33 & 1 \\
\hline & & 4 & Slotting & 4 & 1.5 & 1 \\
\hline \multirow{3}{*}{$\begin{array}{l}\text { Can carrier } \\
\text { shaft }\end{array}$} & \multirow{3}{*}{0.2099} & 1 & Load/unload & 1 & 0.8 & 1 \\
\hline & & 2 & Tuning center & 2 & 4.43 & 1 \\
\hline & & 3 & Mill & 3 & 0.75 & 1 \\
\hline \multirow{4}{*}{ Pulley } & \multirow{4}{*}{0.01235} & 1 & Load/unload & 1 & 0.75 & 1 \\
\hline & & 2 & Turning center & 2 & 2.025 & 1 \\
\hline & & 3 & Mill & 3 & 0.583 & 1 \\
\hline & & 4 & Grinding & 5 & 0.5 & 1 \\
\hline \multirow{3}{*}{ RUD-II } & \multirow{3}{*}{0.01235} & 1 & Load/unload & 1 & 0.833 & 1 \\
\hline & & 2 & Turning center & 2 & 2.17 & 1 \\
\hline & & 3 & Grinding & 5 & 0.833 & 1 \\
\hline \multirow{4}{*}{ Hol-Roller } & \multirow{4}{*}{0.49383} & 1 & Load/unload & 1 & 1.167 & 1 \\
\hline & & 2 & Turning center & 2 & 0.833 & 1 \\
\hline & & 3 & Mill & 3 & 0.667 & 1 \\
\hline & & 4 & Grinding & 5 & 0.5 & 1 \\
\hline \multirow{4}{*}{ Pulley Motor } & \multirow{4}{*}{0.02469} & 1 & Load/unload & 1 & 0.917 & 1 \\
\hline & & 2 & Turning center & 2 & 1.42 & 1 \\
\hline & & 3 & Mill & 3 & 0.5 & 1 \\
\hline & & 4 & Grinding & 5 & 0.667 & 1 \\
\hline \multirow{2}{*}{ Bushing } & \multirow{2}{*}{0.02469} & 1 & Load/unload & 1 & 0.333 & 1 \\
\hline & & 2 & Turning center & 2 & 1.17 & 1 \\
\hline \multirow{3}{*}{$\begin{array}{l}\text { Sprocket } \\
\text { gear }\end{array}$} & \multirow{3}{*}{0.01235} & 1 & Load/unload & 1 & 1.333 & 1 \\
\hline & & 2 & Turning center & 2 & 5.25 & 1 \\
\hline & & 3 & Mill & 3 & 2.5 & 1 \\
\hline \multirow{2}{*}{$\begin{array}{l}\text { Coupling } \\
\text { stud }\end{array}$} & \multirow{2}{*}{0.19751} & 1 & Load/unload & 1 & 1 & 1 \\
\hline & & 2 & Turning center & 2 & 6.15 & 1 \\
\hline
\end{tabular}

\section{RESULT AND DISCUSSION}

\subsection{Operational Parameters}

The average workload was estimated for each station using Eq. (2) and the result is presented in the table 2. The workload of part handling system is also computed based on the number of transport $\left(\mathrm{n}_{\mathrm{t}}\right)$ and mean transport time (which was estimated to be, $\mathrm{t}_{\mathrm{n}+1}=0.5$ hour) similar to the stations workload.

Table 2: Average Workload on Workstations

\begin{tabular}{|c|c|c|}
\hline Station & Description & Average workload (hr.) \\
\hline 1 & Load/Unload & 1.015 \\
\hline 2 & Turning center & 2.815 \\
\hline 3 & Mill & 0.587 \\
\hline 4 & Slotting & 0.019 \\
\hline 5 & Grinding & 0.280 \\
\hline 6 & Material handling system & 1.661 \\
\hline
\end{tabular}


International Journal of Advances in Scientific Research and Engineering (ijasre), Vol 6 (10), October -2020

\subsection{Identification of Bottleneck Station}

The analysis of ratio of maximum work load to number of servers indicated that the turning center (CNC-Lathe) station was the bottleneck station limiting the capacity of the FMS under investigation. The result of the bottleneck station is described in table 3 below.

Table 3: Average workload to number of stations ratio (bottleneck estimation)

\begin{tabular}{|c|l|c|c|l|}
\hline Station & \multicolumn{1}{|c|}{ Description } & Average workload (hr.) & No. of server(s $\left.\mathbf{s}_{\mathbf{i}}\right)$ & $\mathbf{W L}_{\mathbf{i}} / \mathbf{S}_{\mathbf{i}}$ Ratio \\
\hline 1 & Load/Unload & 1.015 & 2 & 0.5075 \\
\hline 2 & Turning center & 2.815 & 3 & $\mathbf{0 . 9 3 8 3}$ \\
\hline 3 & Mill & 0.587 & 3 & 0.1956 \\
\hline 4 & Slotting & 0.019 & 1 & 0.019 \\
\hline 5 & Grinding & 0.280 & 1 & 0.280 \\
\hline 6 & Mat. handling system & 1.661 & 3 & 0.554 \\
\hline
\end{tabular}

\subsection{FMS Performance Measures}

\section{i. $\quad$ Production Rate}

The maximum production rate of all parts of the FMS is obtained as the ratio of number of servers at bottleneck stations to the average workload of the bottleneck station using Eq. (4.)

$$
\boldsymbol{R} \max =\left(\frac{\boldsymbol{S 2}}{\boldsymbol{W L 2}}\right)=\left(\frac{3}{2.815}\right)=1.06572 \text { parts } / \mathrm{hr}
$$

From the above estimation the maximum production rate of all parts for existing system is 1.06572 parts per hour or 8.52576 parts per day (8hours a day). Now, the production rate for each part type can be obtained by using Eq. (5) and results are presented in the table 4.

Table 4: Individual part production rate of exist system per day

\begin{tabular}{|c|l|c|c|}
\hline $\mathrm{S} / \mathrm{N}$ & \multicolumn{1}{|c|}{ Part Type $(\mathbf{j})$} & Part $\operatorname{mix}\left(\mathbf{P}_{\mathbf{j}}\right)$ & Production rate per day $\left(\mathrm{R}_{\max } * \mathrm{P}_{\mathrm{j}}\right)$ \\
\hline 1 & Roller scraper shaft & 0.01235 & 0.105293 \\
\hline 2 & Can carrier shaft & 0.2099 & 1.789557 \\
\hline 3 & Pulley & 0.01235 & 0.105293 \\
\hline 4 & RUD-II & 0.01235 & 0.105293 \\
\hline 5 & Hol-Roller & 0.49383 & 4.210276 \\
\hline 6 & Pulley Motor & 0.02469 & 0.210501 \\
\hline 7 & Bushing & 0.02469 & 0.210501 \\
\hline 8 & Sprocket gear & 0.01235 & 0.105293 \\
\hline 9 & Coupling stud & 0.19751 & 1.683923 \\
\hline
\end{tabular}

The results presented in the table 4 above, indicates that the production rate of the existing flexible manufacturing systems studied is small. Production rate of less than one part means the part is not completely produced during eight hours because the parts are large in size and requires many operations to be performed on it at different stations. Among all the parts under consideration of the study only three part styles (Can carrier shaft, Hol-Roller, \& Coupling stud) can be completed within one day. Since the production rate itself cannot indicate the performance the system, it needs to further estimate the utilization of each station as here under. 
International Journal of Advances in Scientific Research and Engineering (ijasre), Vol 6 (10), October -2020

\section{ii. Utilization of individual workstation}

The percentage utilization of individual workstation is determined by using Eq. (6) and the result is presented in table 5. The utilization result has confirmed that the turning station is the busiest station with 100 percent utilization rate.

Table 5: Mean utilization of workstations

\begin{tabular}{|c|l|c|c|}
\hline Station & \multicolumn{1}{|c|}{ Description } & WLi/Si Ratio & Mean utilization $\mathbf{U}_{\mathbf{i}}(\mathbf{1 0 0 \%})$ \\
\hline 1 & Load/Unload & 0.5075 & 54.09 \\
\hline 2 & Turning center & 0.9383 & 100.00 \\
\hline 3 & Mill & 0.1956 & 20.85 \\
\hline 4 & Slotting & 0.019 & 2.02 \\
\hline 5 & Grinding & 0.280 & 29.84 \\
\hline 6 & Mat. handling system & 0.554 & 59.04 \\
\hline
\end{tabular}

The average workstation utilization $\left(\mathbf{U}_{\mathrm{av}}\right)$ is computed using Eq. (7) which indicated the workstation utilization of $44.31 \%$. Even though the average stations utilization estimated to $44.31 \%$, it does not guarantee in representing the true performance of the system as it averages the utilization to the number of stations without considering the number of severs. Therefore, the overall FMS utilization is determined using Eq. (8) found to be $50.259 \%$ which indicates that the system is idle for $50 \%$ of the available time. This value of percentage utilization of the system is an indicative of poor capacity utilization.

\section{iii. Number of busy servers}

Number of busy servers at each station was determined using Eq. (9) and the result is represented in table 6 below.

Table 6: Number of busy servers at each station

\begin{tabular}{|c|l|c|c|c|}
\hline Station & \multicolumn{1}{|c|}{ Description } & No. of Server & $\begin{array}{c}\text { Workload, WLi } \\
(\mathrm{hr})\end{array}$ & Busy servers $\left(\mathbf{B S}_{\mathbf{i}}\right)$ \\
\hline 1 & Load/Unload & 2 & 1.015 & 1.08 \\
\hline 2 & Turning center & 3 & 2.815 & 3.00 \\
\hline 3 & Mill & 3 & 0.587 & 0.63 \\
\hline 4 & Slotting & 1 & 0.019 & 0.02 \\
\hline 5 & Grinding & 1 & 0.280 & 0.30 \\
\hline 6 & Mat. handling system & 3 & 1.661 & 1.77 \\
\hline
\end{tabular}

The result in table 6 for busy servers indicates that only station two servers are busy whereas other stations are more than $50 \%$ idle. For example, milling station (station-3) is almost idle and only about $21 \%$ of its capacity is utilized.

Finally, the manufacturing lead time, work in process (in built-queue length), and waiting time is determined through the application of the extended bottleneck model defined by Eq. (10 and 11). Since the number of part mix in the system for this case are nine, and the critical values of $\mathrm{N}$ computed equations and guidelines for the extended model (Groover, 2015; Jovanovi, 2015) is 6.8 parts per hour which is less than the expected number of parts in the system. Therefore, the second case provided by Groover ( 2015)and Jovani (2015) was applied to estimate MLT and $\mathrm{T}_{\mathrm{w}}$ for existing FMS and found to 8.445 hours and 20.07 hour, respectively. Depending on the findings of the analysis presented in this section, it can be concluded that the existing system is operating very inefficiently yielding in high work in process inventory.

\section{PROPOSED FLEXIBLE MANUFACTURING SYSTEM}

\subsection{Sizing the FMS}

The analysis result also revealed that the resources are distributed inefficiently with improper allocation of workloads. Therefore, an optimal number of servers are determined and FMS was sized to balance the workloads and remove the bottlenecks from the current system studied. In the course of balancing the existing system, the system servers are 
increased to 20 servers. After including additional servers to the system an operational and performance parameters are estimated as like done for the existing system.

\subsection{Production rate of proposed manufacturing system}

The maximum production rate for the modified manufacturing system is constrained by the material handling system which is concluded as the bottleneck station in the system. The same procedure and equation used to compute production rate for an existing system is followed to estimate the maximum production rate for the proposed FMS. The maximum production rate of 2.408 parts per hour or 19.266 parts per day is obtained for the new proposed system using Eq. 4. The individual part production rate for the system was calculated applying Eq. (5) as done for an existing system.

\subsection{Utilization of workstation for the proposed manufacturing system}

The amount of time a specific workstation is working and not in idle condition is defined as mean utilization computed by multiplying the maximum production by the workload to number of servers' ratio and the result is represented in table 7 .

Table 7: Workstation utilization of the proposed FMS

\begin{tabular}{|c|l|c|c|c|c|c|}
\hline S/N & \multicolumn{1}{|c|}{ Station } & $\begin{array}{c}\text { No. of } \\
\text { Server }\end{array}$ & $\begin{array}{c}\text { Workload, } \\
\text { WLi }(\mathrm{hr} .)\end{array}$ & $\begin{array}{c}\text { WLi/Si } \\
\text { Ratio }\end{array}$ & $\begin{array}{c}\text { Utilization } \\
(\%), \mathrm{U}_{\mathrm{i}}\end{array}$ & $\begin{array}{c}\text { Busy servers } \\
\left(\mathrm{BS}_{\mathrm{i})}\right.\end{array}$ \\
\hline 1 & Load/Unload & 3 & 1.015 & 0.338 & 81.47 & 2.44 \\
\hline 2 & Turning center & 8 & 2.815 & 0.352 & 84.73 & 6.78 \\
\hline 3 & Mill & 3 & 0.587 & 0.196 & 47.12 & 1.41 \\
\hline 4 & Slotting & 1 & 0.019 & 0.019 & 4.58 & 0.05 \\
\hline 5 & Grinding & 1 & 0.280 & 0.280 & 67.42 & 0.67 \\
\hline 6 & Mat. handling system & 4 & 1.661 & 0.415 & 100 & 4.00 \\
\hline
\end{tabular}

The overall utilization of the proposed system has calculated using equation and the modification has improved the utilization from $50.259 \%$ to $76.78 \%$. The seventh column of table 7 indicates the percentage utilization of workstations and it is observed the proposed or modified FMS gives better utilization of stations. Except station three and four which has utilization below 50\%, the remaining stations have utilization above 60 per cent. The figure below presents the utilization of proposed FMS against the utilization of resources of existing FMS.

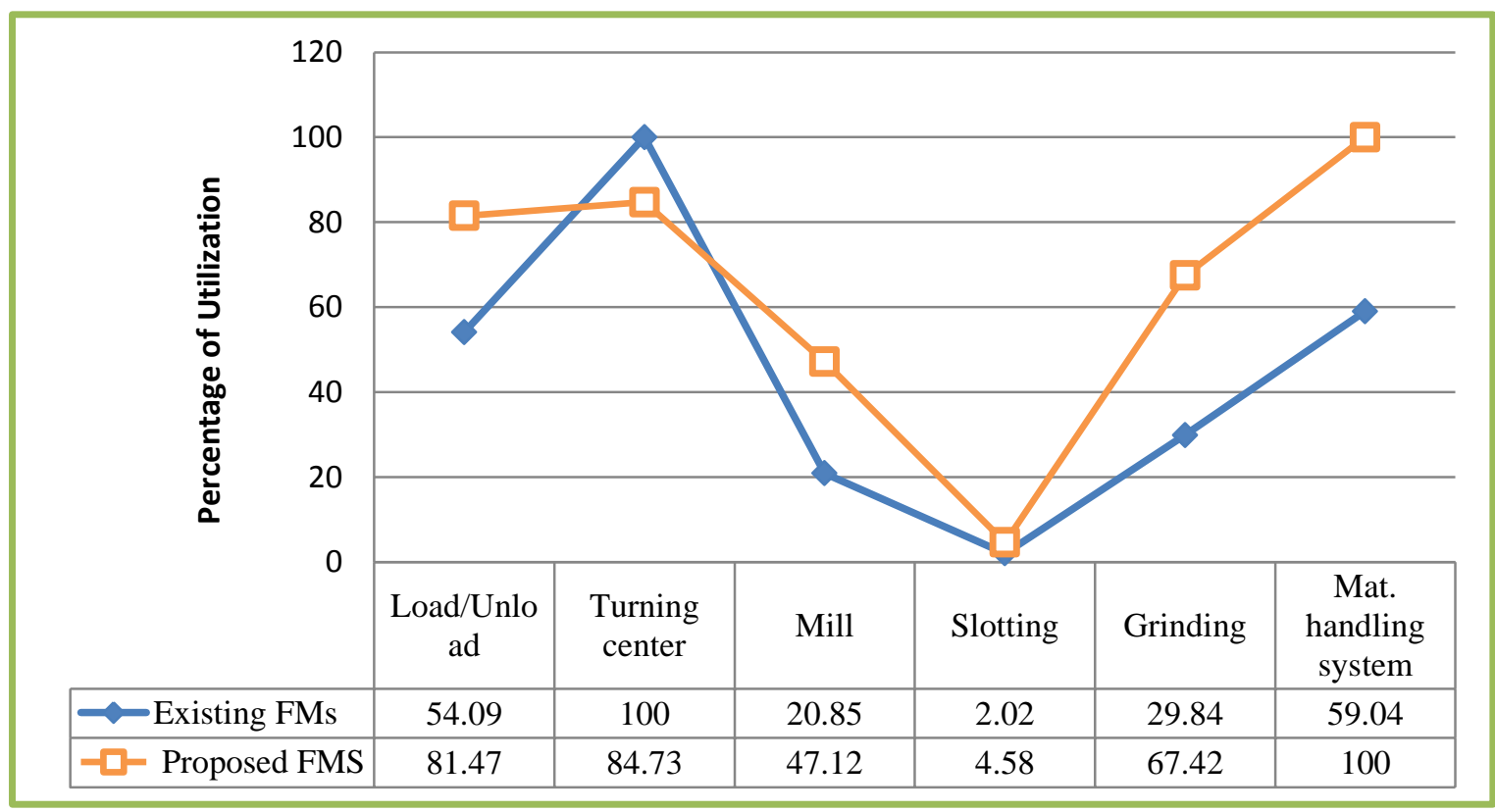

Figure 1 Existing Vs Proposed FMSs Utilization 
The comparison of the existing and proposed FMS corresponding to the production rate, total number of servers, overall utilization, manufacturing lead time, and waiting time is represented in the table 5.2.

Table 8: Performance of FMS (Existing Vs. Proposed)

\begin{tabular}{|l|l|l|l|}
\hline S/N & Performance Parameters & Existing FMS & Proposed FMS \\
\hline 1 & No of Servers & 13 & 20 \\
\hline 2 & Overall Utilization & 50.259 & 76.779 \\
\hline 3 & Production rate & 1.06572 parts $/ \mathrm{hr}$. & 2.408 parts $/ \mathrm{hr}$. \\
\hline 4 & Manufacturing lead time & $8.445 \mathrm{hr}$. & $3.737 \mathrm{hr}$. \\
\hline 5 & Waiting time & $2.07 \mathrm{hr}$. & 0 \\
\hline
\end{tabular}

\section{CONCLUSIONS}

This paper has presented the application of quantitative techniques; bottleneck model and extended bottleneck model evaluate the production performance of FMS with real data through case study. Applying the two models various operating and performance parameters were calculated and compared with the performance of the proposed FMS. The study has revealed that the workload per server of the existing system is higher in turning center which is also established by the fact that the machine utilization of this station is $100 \%$. Therefore, the turning center is identified as the station constraining the production rate of the existing system and concluded as a bottleneck station.

The study has also examined the utilization of workstations and the result indicated the under-utilization of resources due to imbalance workload distribution. In order to improve the performance of the existing system, it is important to propose a new FMS by shifting the bottleneck station to another less import station thus workloads can be distributed adequately through each station. The improvement is done by adding seven servers to the existing and a new FMS is proposed. The proposed system has indicated a promising improvement in each operational performance measures such production rate, overall utilization, manufacturing lead time, etc. The modified FMS has indicated an improvement of $26.52 \%$ in the overall utilization of workstations, 1.342 parts per hour in production rate and reduces the manufacturing lead time 4.708 hours.

Though the findings of the study have an importance for managers in guiding performance measurement and decision making, the analytic approach applied to determine the performance of the system assumes certainty regarding all the system parameters such as processing time, production rate, and demand for products, but in real application these parameters will change over planning horizon Therefore, developing a stochastic model for the analysis of FMS performance and proposing a performance improvement method will be the future research prospect in FMS field. Another limitation of the paper is financial analysis were not considered thus, including financial analysis in the study is another research topic to extend the work.

\section{REFERENCES}

Abazari, A. M., Solimanpur, M., \& Sattari, H. (2012). Optimum loading of machines in a flexible manufacturing system using a mixed-integer linear mathematical programming model and genetic algorithm. Computers and Industrial Engineering, 62(2), 469-478. https://doi.org/10.1016/j.cie.2011.10.013

De Toni, A., \& Tonchia, S. (1998). International Journal of Production Research Manufacturing flexibility: A literature review Manufacturing - exibility: a literature review. In International Journal of Production Research int. j. prod. res (Vol. 366, Issue 6). https://doi.org/10.1080/002075498193183

Ebrahimi, A. (2015). Determining the Optimal Performance of Flexible Manufacturing Systems using Network Analysis and Simulation Process. 4, 12-17.

El-Tamimi, A. M., Abidi, M. H., Mian, S. H., \& Aalam, J. (2012). Analysis of performance measures of flexible manufacturing system. Journal of King Saud University - Engineering Sciences, 24(2), 115-129. https://doi.org/10.1016/j.jksues.2011.06.005

Groover, M. P. (2015). Automation, Production Systems, ad Computer-Integrated Manufacturing (4th ed.). Pearson Higher Eduation, Inc.

Jovanovi, S. (2015). Flexible Manufacturing Systems and Quantitative Anlysis of Flexible Manufacturing Systems. 
International Journal of Advances in Scientific Research and Engineering (ijasre), Vol 6 (10), October -2020 International Journal of Computer Applictions, 132(1), 6-14.

Maccarthy, B. L., \& Liu, J. (1993). A new classification scheme for flexible manufacturing systems. International Journal of Production Research, 31(2), 299-309. https://doi.org/10.1080/00207549308956726

Mahmood, K., Karaulova, T., Otto, T., \& Shevtshenko, E. (2017). Performance Analysis of a Flexible Manufacturing System (FMS). Procedia CIRP, 63, 424-429. https://doi.org/10.1016/j.procir.2017.03.123

Rohit, Pandey; Nishant, Sharma; Arvind, S. T. et al. (1984). Performance Evaluation of Flexible Manufacturing Systems. IEEE Transactions on Systems, Man and Cybernetics, SMC-14(4), 606-617. https://doi.org/10.1109/TSMC.1984.6313332

Sharma, R. (2013). Implementation Issues in FMS : A Literature Review. International Journal of Innovations in Engineering and Technology, 2(2).

Singholi, A., Chhabra, D., \& Ali, M. (2010). Towards improving the performance of flexible manufacturing system: A case study. Journal of Industrial Engineering and Management, 3(1), 87-115. https://doi.org/10.3926/jiem.2010.v3n1.p87-115

Small, K. A. (2015). The bottleneck model: An assessment and interpretation. Economics of Transportation, 4(1-2), 110-117. https://doi.org/10.1016/j.ecotra.2015.01.001

Solberg, J. J. (1981). Capacity planning with a stochastic workflow model. AIIE Transactions, 13(2), 116-122. https://doi.org/10.1080/05695558108974543

Taha, A. H. (2015). Flexible Manufacturing Systems and Quantitative Anlysis of Flexible Manufacturing Systems. Journals of Advanced Science and Engineering Research, 5(1), 1-8. https://doi.org/10.5120/ijca2015907243

Yadav, A., \& Jayswal, S. C. (2018). Modelling of flexible manufacturing system: a review. International Journal of Production Research, 56(7), 2464-2487. https://doi.org/10.1080/00207543.2017.1387302 